OPEN ACCESS

Edited by:

Jasvinder Chawla,

Loyola University Medical Center and

Hines VA Hospital, USA

Reviewed by:

Markus Kofler,

Hochzirl Hospital, Austria

*Correspondence:

A. Arturo Leis

aleis@mmrcrehab.org,

leis.ange/@mayo.edu

Specialty section:

This article was submitted to

Neuromuscular Diseases,

a section of the journal

Frontiers in Neurology

Received: 24 May 2015 Accepted: 22 January 2016 Published: 11 February 2016

Citation:

Leis AA, Ross MA, Verheijde $J L$ and Leis JF (2016) Immunoablation and Stem Cell Transplantation in Amyotrophic Lateral Sclerosis: The Ultimate Test for the Autoimmune Pathogenesis Hypothesis.

Front. Neurol. 7:12.

doi: 10.3389/fneur.2016.00012

\section{Immunoablation and Stem Cell Transplantation in Amyotrophic Lateral Sclerosis: The Ultimate Test for the Autoimmune Pathogenesis Hypothesis}

\author{
A. Arturo Leis ${ }^{1,2 *}$, Mark A. Ross ${ }^{1}$, Joseph L. Verheijde ${ }^{3}$ and Jose F. Leis ${ }^{4}$ \\ ${ }^{1}$ Department of Neurology, Mayo Clinic Arizona, Scottsdale, AZ, USA, ${ }^{2}$ Center for Neuroscience and Neurological Recovery, \\ Methodist Rehabilitation Center, Jackson, MS, USA, ${ }^{3}$ Department of Physical Medicine and Rehabilitation, Mayo Clinic \\ Arizona, Scottsdale, AZ, USA, ${ }^{4}$ Division of Hematology Oncology, Mayo Clinic Arizona, Phoenix, AZ, USA
}

Keywords: autoimmunity, amyotrophic lateral sclerosis, stem cell transplantation, immunosuppression

Amyotrophic lateral sclerosis (ALS) is a fatal neurodegenerative disorder characterized by a progressive death of motor neurons for which there is no cure or effective treatment. The cause of ALS and the specific mechanisms of neuronal death remain unknown. However, considerable evidence supports the existence of autoimmune mechanisms contributing to pathogenesis in ALS, including biochemical, morphological, pharmacological, and physiological studies performed in animal models, cell culture, or with ex vivo preparations (1-6). Typical hallmarks of autoimmunity, such as circulating immune complexes, higher frequency of a particular histocompatibility type, or association with other autoimmune diseases, have also been reported $(7,8)$. An important marker of autoimmunity is the degree of T-lymphocytic infiltration in the anterior horn of the spinal cord from ALS patients $(9,10)$. Using monoclonal antibodies against T-cells, B-cells, and macrophages, almost $80 \%$ of the specimens show a cellular mononuclear infiltration. The cellular composition of the spinal cord inflammation consists of subsets of suppressor or cytotoxic T-cells and macrophages in the anterior and lateral corticospinal tracts and anterior horns (10). T-helper cells are also observed in proximity to corticospinal tract degeneration (11). Hence, inflammation in ALS spinal cord and brain appears to be primarily due to T-cells and macrophages (12), and aberrant macrophage activity is believed by many investigators to contribute to the pathology underlying ALS. This may explain the recent promising results of an ALS phase 2 clinical trial of NP001, a regulator of inflammatory macrophage activity (13). Although the predefined endpoints in this study did not reach statistical significance, administration of NP001 was associated with cessation in disease progression in $27 \%$ of patients, approximately 2.5 times greater than the percentage in patients on placebo. Two major plasma markers of inflammation, interleukin-18 (IL-18) and lipopolysaccharide (LPS), differentiated NP001 responders from non-responders, suggesting that the subgroup of patients with greater baseline biomarkers of neuroinflammation experienced the most benefit (13). Additional evidence pointing toward pathologic involvement of autoimmune processes has been the finding that immunoglobulins from ALS patients have been shown to cause apoptosis of motor neurons in primary spinal cord cultures (14) and that passive transfer of immunoglobulins to mice caused abnormalities at motor end-plates and degeneration of motor neurons $(4,15)$. These findings suggest that antibodies can contribute to disease pathogenesis. Increased levels of interleukins IL-17 and IL-23 have also been found in serum and cerebrospinal fluid of ALS patients (16). This increment is thought to be a sign of T-helper 17 (Th17) activation, a subset of T-cells suggested to be crucial in destructive autoimmunity. Astrocytes have also been shown to participate in the pathogenesis of ALS by producing a microenvironment toxic to motor neurons through increased neuroinflammation, oxidative damage, 
and glutamate excitotoxicity $(17,18)$. Overactivated astroglia produce high levels of protein S100B and other proinflammatory factors, which exacerbate neuroinflammation. The extracellular effects of S100B vary, depending on the concentration attained; at nanomolar concentrations, S100B is trophic to neurons, but at micromolar concentrations, $\mathrm{S} 100 \mathrm{~B}$ causes neuronal apoptosis $(19,20)$. Many of the effects of S100B on neurons are transduced by the receptor for advanced glycation end-products (RAGE), which participates in the pathophysiology of brain inflammatory disorders by regulating several inflammation-related events, including activation and migration of microglia and neutrophils to inflammatory sites (19-21). Extravasation of S100B into the systemic circulation can also trigger a pathologic autoimmune reaction with circulating antibodies that may re-enter the CNS to initiate an autoimmune response (22). Hence, S100B can be viewed as an astrocytic endokine that can act as an immunoregulator to participate in inflammation and autoimmunity. Additional support for the autoimmune pathogenesis hypothesis is the finding that ALS has recently been included in the spectrum of neurologic manifestations associated with voltage-gated potassium channel (VGKC) autoimmunity (23-25).

Because of the large body of evidence suggesting a neurotoxic effect of the immune response in ALS, numerous therapeutic trials based on the autoimmune pathogenesis hypothesis have been performed. However, these studies have failed to demonstrate improvement in motor function. Immunosuppressive drugs, such as corticosteroids, azathioprine, cyclophosphamide, cyclosporine, or combination pharmacotherapy, as well as immunotherapy with plasmapheresis or intravenous immunoglobulins, have not altered disease progression (26-28). Moreover, in what had been considered the ultimate trial in immunosuppression for ALS, total lymphoid irradiation (TLI), which produces a more powerful and prolonged immunosuppression, did not benefit patients with ALS (29). The conclusion from these therapeutic trials was that autoimmune mechanisms did not contribute to the pathogenesis in ALS. However, all negative trials based on the autoimmune pathogenesis hypothesis were performed in the latter decades of the 1900s, and TLI and the immunosuppressive drugs used in these early trials are no longer considered today's gold standard in immunosuppression.

Since 1996, intensive immunosuppression followed by autologous hematopoietic stem cell transplantation (AHSCT) to renew the immune system has been used for the treatment of severe autoimmune diseases refractory to approved therapies (30). The largest cohort studied worldwide (European Group for Blood and Marrow Transplantation registry between 1996 and 2007) evaluated the long-term outcomes of these transplants in 900 patients with various autoimmune diseases including multiple sclerosis, systemic sclerosis, systemic lupus erythematosus, rheumatoid arthritis, juvenile arthritis, and hematologic immune cytopenia (30). Among all patients, the 5-year survival was $85 \%$ and the progression-free survival $43 \%$. Age $<35$ years and transplantation after the year 2000 were associated with progression-free survival. This worldwide study showed that profound immunosuppression and AHSCT can induce sustained remissions in patients with severe systemic autoimmune diseases refractory to conventional therapy (30). Furthermore, it underscored the therapeutic principle that in all successfully treated autoimmune diseases, there are intractable cases that subsequently improve with more aggressive immunotherapy. Hence, the failure of prior ALS therapeutic trials based on the autoimmune pathogenesis hypotheses may have reflected a relative inability to achieve the intense immunosuppression needed to abolish the immune mechanisms contributing to disease progression.

In recent years, it has been recognized that stem cells have the ability to provide numerous potential benefits in ALS (31) and a variety of stem cell-based therapies are underway (32). The majority of these studies have assessed the therapeutic efficacy of different cellular delivery mechanisms, including intracranial, motor cortex, intrathecal, intraventricular, intraspinal, and intravenous, utilizing various types of stem cells to renew, repair, or replace damaged motor neurons. However, perhaps because of the earlier negative trials that discredited the autoimmune pathogenesis hypothesis, these stem cell trials do not emphasize immunosuppression as a therapeutic strategy. Rather, the injection of various types of stem cells into brain or spinal cord for the purpose of replacement or repair of damaged neurons, without antecedent immunosuppression, is perceived as holding the greatest potential for eventual success in the ALS patient (33). The omission of immunosuppression as a therapeutic strategy is problematic, since copious scientific studies support a role for neurotoxic effects of the immune response in ALS. Even the pioneers who used TLI and other immunosuppressive agents in the 1990s recognized that these agents did not completely abrogate cellular or antibody responses and that more powerful immunosuppression might still alter the course of ALS (34). Moreover, in a relatively recent study of allogeneic hematopoietic stem cell transplantation in ALS, transplantation preceded by only a non-myeloablative conditioning regimen did not benefit ALS patients, despite reported engraftment of stem cells at sites of motor neuron pathology (35). This study provided evidence that stem cell transplantation in the absence of immunoablation may not deliver the greatest potential for success in the ALS patient. In this historical context, the current rush to inject stem cells into the central nervous system without antecedent immunosuppression seems premature because the most definitive trial in immunosuppression for ALS has not yet been performed. Accordingly, a step backward may be required to go forward in the therapeutic fight against ALS.

In this Opinion piece, we propose the use of immunoablation as a therapeutic strategy to abolish the potential neurotoxic effects of the immune response in ALS. It is not our intent to comment on the use of stem cells to renew, repair, or replace damaged motor neurons. In our therapeutic model, reinfused stem cells are required only to replenish or "reboot" the immune system. Without this step, patients undergoing immunoablation will die of opportunistic infections. Hence, immunoablation cannot be performed without subsequent stem cell infusion.

We are aware that there may be concern about submitting ALS patients to immunoablation. However, for almost 20 years, this type of intensive immunosuppression followed by stem cell transplantation has been used with success for the treatment of severe autoimmune diseases (30). Immunoablation and stem cell transplantation is also a standard of care in the treatment of hematological malignancies. In ALS patients, as in patients with 
autoimmune diseases or hematological malignancies, immunoablation would be expected to be followed by regeneration of a new self-tolerant immune system derived from the reinfused stem cells. The abundance of data suggesting that neuroinflammation contributes to ALS pathogenesis warrants such a trial. The therapeutic concept that in all autoimmune diseases there are intractable cases that subsequently improve with more aggressive immunotherapy also demands the most definitive trial of immunosuppression in ALS. Only then can the autoimmune pathogenesis hypothesis be revived or be laid to eternal rest.

\section{REFERENCES}

1. Pagani MR, Gonzalez LE, Uchitel OD. Autoimmunity in amyotrophic lateral sclerosis: past and present. Neurol Res Int (2011) 2011:497080. doi:10.1155/2011/497080

2. Engelhardt JI, Siklos L, Komuves L, Smith RG, Appel SH. Antibodies to calcium channels from ALS patients passively transferred to mice selectively increase intracellular calcium and induce ultrastructural changes in motoneurons. Synapse (1995) 20:185-99. doi:10.1002/syn.890200302

3. Appel SH, Smith RG, Engelhardt JI, Stefani E. Evidence for autoimmunity in amyotrophic lateral sclerosis. J Neurol Sci (1994) 124:S14-9. doi:10.1016/0022-510X(94)90171-6

4. Pullen AH, Demestre M, Howard RS, Orrell RW. Passive transfer of purified IgG from patients with amyotrophic lateral sclerosis to mice results in degeneration of motor neurons accompanied by $\mathrm{Ca} 2+$ enhancement. Acta Neuropathol (2004) 107:35-46. doi:10.1007/s00401-003-0777-z

5. Pagani MR, Reisin RC, Uchitel OD. Calcium signaling pathways mediating synaptic potentiation triggered by amyotrophic lateral sclerosis IgG in motor nerve terminals. J Neurosci (2006) 26:2661-72. doi:10.1523/ JNEUROSCI.4394-05.2006

6. Fratantoni SA, Weisz G, Pardal AM, Reisin RC, Uchitel OD. Amyotrophic lateral sclerosis IgG-treated neuromuscular junctions develop sensitivity to L-type calcium channel blocker. Muscle Nerve (2000) 23:543-50. doi:10.1002/ (SICI)1097-4598(200004)23:4<543::AID-MUS13>3.0.CO;2-S

7. Antel JP, Arnason BG, Fuller TC, Lehrich JR. Histocompatibility typing in amyotrophic lateral sclerosis. Arch Neurol (1976) 33:423-5. doi:10.1001/ archneur.1976.00500060029007

8. Oldstone MB, Wilson CB, Perrin LH, Norris FH Jr. Evidence for immune-complex formation in patients with amyotrophic lateral sclerosis. Lancet (1976) 2:169-72. doi:10.1016/S0140-6736(76)92345-X

9. Troost D, Van den Oord JJ, de Jong JM, Swaab DF. Lymphocytic infiltration in the spinal cord of patients with amyotrophic lateral sclerosis. Clin Neuropathol (1989) 8:289-94.

10. Troost D, Van den Oord JJ, Vianney de Jong JM. Immunohistochemical characterization of the inflammatory infiltrate in amyotrophic lateral sclerosis. Neuropathol Appl Neurobiol (1990) 16:401-10. doi:10.1111/j.1365-2990.1990. tb01276.x

11. Engelhardt JI, Tajti J, Appel SH. Lymphocytic infiltrates in the spinal cord in amyotrophic lateral sclerosis. Arch Neurol (1993) 50:30-6. doi:10.1001/ archneur.1993.00540010026013

12. Graves MC, Fiala M, Dinglasan LA, Liu NQ, Sayre J, Chiappelli F, et al. Inflammation in amyotrophic lateral sclerosis spinal cord and brain is mediated by activated macrophages, mast cells and T cells. Amyotroph Lateral Scler (2004) 5:213-9. doi:10.1080/14660820410020286

13. Miller RG, Block G, Katz JS, Barohn RJ, Gopalakrishnan V, Cudkowicz M, et al. Randomized phase 2 trial of NP001-a novel immune regulator: safety and early efficacy in ALS. Neurol Neuroimmunol Neuroinflamm (2015) 2(3):e100. doi:10.1212/NXI.0000000000000100

14. Demestre M, Pullen A, Orrell RW, Orth M. ALS-IgG-induced selective motor neurone apoptosis in rat mixed primary spinal cord cultures. J Neurochem (2005) 94:268-75. doi:10.1111/j.1471-4159.2005.03184.x

15. Appel SH, Engelhardt JI, García J, Stefani E. Immunoglobulins from animal models of motor neuron disease and from human amyotrophic lateral

\section{AUTHOR CONTRIBUTIONS}

All authors listed have made substantial, direct, and intellectual contribution to the work and approved it for publication.

\section{ACKNOWLEDGMENTS}

This work was supported in part by the Wilson Research Foundation and the Methodist Rehabilitation Center, Jackson, MS, USA.

sclerosis patients passively transfer physiological abnormalities to the neuromuscular junction. Proc Natl Acad Sci U S A (1991) 88:647-51. doi:10.1073/ pnas.88.2.647

16. Rentzos M, Rombos A, Nikolaou C, Zoga M, Zouvelou V, Dimitrakopoulos A, et al. Interleukin-17 and interleukin-23 are elevated in serum and cerebrospinal fluid of patients with ALS: a reflection of Th17 cells activation? Acta Neurol Scand (2010) 122:425-9. doi:10.1111/j.1600-0404.2010.01333.x

17. Rossi D, Volterra A. Astrocytic dysfunction: insights on the role in neurodegeneration. Brain Res Bull (2009) 80:224-32. doi:10.1016/j. brainresbull.2009.07.012

18. Blackburn D, Sargsyan S, Monk PN, Shaw PJ. Astrocyte function and role in motor neuron disease: a future therapeutic target? Glia (2009) 57:1251-64. doi:10.1002/glia.20848

19. Bianchi R, Kastrisianaki E, Giambanc I, Donato R. S100B protein stimulates microglia migration via RAGE-dependent up-regulation of chemokine expression and release. J Biol Chem (2011) 286:7214-26. doi:10.1074/jbc. M110.169342

20. Bianchi R, Adami C, Giambanco I, Donato R. S100B binding to RAGE in microglia stimulates COX-2 expression. J Leukoc Biol (2007) 81:108-18. doi:10.1189/jlb.0306198

21. Kuwar RB, Stokic DS, Leis AA, Bai F, Paul AM, Fratkin JD, et al. Does astroglia protein S100B contribute to West Nile neuro-invasive syndrome? J Neurol Sci (2015) 358:243-52. doi:10.1016/j.jns.2015.09.003

22. Bargerstock E, Puvenna B, Iffland P, Falcone T, Hossain M, Vetter S, et al. Is peripheral immunity regulated by blood-brain barrier permeability changes? PLoS One (2014) 9(7):e101477. doi:10.1371/journal.pone.0101477

23. Nwosu VK, Royer JA, Stickler DE. Voltage gated potassium channel antibodies in amyotrophic lateral sclerosis. Amyotroph Lateral Scler (2010) 11:392-4. doi:10.3109/17482960903452283

24. Chhetri SK, Majeed T, Lekwuwa G, Boothman B. Very high titers of voltage-gated potassium channel antibodies in a patient with amyotrophic lateral sclerosis. Muscle Nerve (2015) 51:147. doi:10.1002/mus.24460

25. Sato A, Sakai N, Shinbo J, Hashidate H, Igarashi S, Kakita A, et al. An autopsy case of amyotrophic lateral sclerosis with prominent muscle cramps, fasciculation, and high titer of anti-voltage gated potassium channel (VGKC) complex antibody. Rinsho Shinkeigaku(2014) 54:32-7. doi:10.5692/clinicalneurol.54.32

26. Olarte MR, Schoenfeldt RS, McKiernan G, Rowland LP. Plasmapheresis in amyotrophic lateral sclerosis. Ann Neurol (1980) 8:644-5. doi:10.1002/ ana.410080625

27. Brown RH Jr, Hauser SL, Harrington H, Weiner HL. Failure of immunosuppression with a ten- to 14-day course of high-dose intravenous cyclophosphamide to alter the progression of amyotrophic lateral sclerosis. Arch Neurol (1986) 43:383-4. doi:10.1001/archneur.1986.00520040063021

28. Appel SH, Stewart SS, Appel V, Harati Y, Mietlowski W, Weiss W, et al. A double-blind study of the effectiveness of cyclosporine in amyotrophiclateral sclerosis. Arch Neurol (1988) 45:381-6. doi:10.1001/archneur.1988.00520280027011

29. Drachman DB, Chaudhry V, Cornblath D, Kuncl RW, Pestronk A, Clawson L, et al. Trial of immunosuppression in amyotrophic lateral sclerosis using total lymphoid irradiation. Ann Neurol (1994) 35:142-50. doi:10.1002/ ana.410350205

30. Farge D, Labopin M, Tyndall A, Fassas A, Mancardi GL, Van Laar J, et al. Autologous hematopoietic stem cell transplantation for autoimmune diseases: an observational study on 12 years' experience from the European group for 
blood and marrow transplantation working party on autoimmune diseases. Haematologica (2010) 95:284-92. doi:10.3324/haematol.2009.013458

31. Thonhoff JR, Ojeda L, Wu P. Stem cell-derived motor neurons: applications and challenges in amyotrophic lateral sclerosis. Curr Stem Cell Res Ther (2009) 4:178-99. doi:10.2174/157488809789057392

32. Lunn JS, Sakowski SA, Feldman EL. Concise review: stem cell therapies for amyotrophic lateral sclerosis: recent advances and prospects for the future. Stem Cells (2014) 32:1099-109. doi:10.1002/stem.1628

33. ALS Worldwide. Stem Cells (2010). Available from: http://www.alsworldwide. org

34. Haverkamp LJ, Smith RG, Appel SH. Letter to the editor. Trial of immunosuppression in amyotrophic lateral sclerosis using total lymphoid irradiation. Reply: Drachman, D.B., Chaudhry, V., Cornblath, D., Kuncl, R.W., Pestronk, A., Clawson, L., et al. Ann Neurol (1994) 36:253-4. doi:10.1002/ana.410360225
35. Appel SH, Engelhardt JI, Henkel JS, Siklos L, Beers DR, Yen AA. Hematopoietic stem cell transplantation in patients with sporadic amyotrophic lateral sclerosis. Neurology (2008) 71:1326-34. doi:10.1212/01.wnl.0000327668.43541.22

Conflict of Interest Statement: The authors declare that the research was conducted in the absence of any commercial or financial relationships that could be construed as a potential conflict of interest.

Copyright (c) 2016 Leis, Ross, Verheijde and Leis. This is an open-access article distributed under the terms of the Creative Commons Attribution License (CC BY). The use, distribution or reproduction in other forums is permitted, provided the original author(s) or licensor are credited and that the original publication in this journal is cited, in accordance with accepted academic practice. No use, distribution or reproduction is permitted which does not comply with these terms. 